\title{
A EDUCAÇÃo FíSICA CAMINHANDO COM A EDUCAÇÃO AMBIENTAL
}

Fernando Garcez de Melo ${ }^{1}$

\section{Resumo}

O intuito desse texto é refletir sobre as possibilidades de a Educação Física como componente curricular ser mais um caminho para a Educação Ambiental, um modo de alargar a linguagem sobre o tema, de colaborar para uma descrição densa da temática. Destacamos como eixo analítico desse trabalho, a perspectiva de Educação Ambiental crítica, complexa e reflexiva, de modo consonante com a ótica dos esportes de aventuras e atividades de lazer na natureza como caminho para a Educação Ambiental e com a visão de Educação Ambiental como política pública, que destaca a questão da gestão ambiental. Esses são os elementos balizadores para estabelecermos um vínculo entre ambiente-educação-corpo-lazer-esporte, da qual almejamos suscitar breves notas para o trabalho docente na Educação Física. Por essa via que esperamos inquietar os profissionais do espaço escolar para apresentações de perspectivas e soluções para uma sociedade sustentável.

Palavras-chave: Educação Física; Educação Ambiental; lazer; esporte.

${ }^{1}$ Faculdade de Ciências da Saúde, Curso de Educação Física.. Universidade do Estado de Mato Grosso. E-mail: garcez@unemat.br

Revbea, São Paulo, V. 12, № 5: 156-169, 2017. 


\section{Introdução}

O debate acerca da questão ambiental é sobre as próprias condições e possibilidades de mantermos a vida no planeta. Em razão de um sistema econômico e uma racionalidade instrumental que extrai recursos naturais do meio ambiente muito acima do suportável, os problemas que assolam o meio ambiente tornou-se agenda constante e prioritária das nações de todos os continentes e dos principais órgãos mundiais. No Brasil, criou o Ministério de Meio Ambiente a fim de criar ações de conservação e de combate à exploração de recursos naturais. Como desdobramento, realçamos o importante valor da Educação Ambiental, instituída pela lei 9.795/1999. Nela podemos observar a responsabilidade de todos os cidadãos, tendo a escola como espaço privilegiado para a difusão de ações de preservação e a criação de novas possibilidades. Uma dessas ações são as Comissões de Meio Ambiente e Qualidade de Vida (COM-VIDAS), criada em 2000, e visa permitir aos jovens que sejam protagonistas nas ações de cuidado e de estabelecer novas sociabilidades com a natureza e espaços urbanos. Nesse sentido, pensar a questão ambiental é elaborar estratégias de Educação Ambiental, para que as ações sejam de preservação, recuperação e sustentáveis. Educar os jovens na questão ambiental é fundamental para o desenvolvimento sustentável. E, para tanto, estreitar laços com a natureza é decisivo. Portanto, a realização de práticas corporais de lazer e aventuras esportivas na natureza é excelente caminho para formar uma nova relação homem-natureza, pautado na ética da sensibilidade e na política de igualdade.

Nesse ínterim, o intuito desse texto é refletir sobre as possibilidades de a Educação Física como componente curricular ser mais um caminho para a Educação Ambiental, um modo de alargar a linguagem sobre o tema, de colaborar para uma descrição densa da temática. Destacamos como eixo analítico desse trabalho, a perspectiva de Educação Ambiental crítica, complexa e reflexiva (JACOBI, 2005), de modo consonante com a ótica dos esportes de aventuras e atividades de lazer na natureza como caminho para a Educação Ambiental (MARINHO, INÁCIO, 2007; MARINHO, 2004) e com a visão de Educação Ambiental como política pública, que destaca a questão da gestão ambiental (SORRENTINO et al., 2005). Essa perspectiva ancora-se numa análise crítica por entender a sociedade no seu curso histórico e, portanto, produzida pelos homens e mulheres, classes e grupos, ainda que em condições não escolhidas. É complexa por considerar a diversidade de fatores e contingências que influenciam nas questões ambientais, combatendo a visão única e unilateral. E é reflexiva "por meio da visão do meio ambiente como um campo de conhecimento e significados socialmente construídos, que é perpassado pela diversidade cultural e ideológica e pelos conflitos de interesse" (JACOBI, 2005, p. 244). 


\section{O vínculo ambiente-educação-corpo-lazer-esporte}

A sociedade contemporânea é tecida, continuamente, pelos seres humanos numa imbricada conjuntura de problemáticas e perspectivas, avanços e retrocessos, de modo a impactar, decididamente, no meio ambiente e recursos naturais. A configuração do sistema econômico, resultante tanto da revolução industrial quanto da chamada revolução pós-industrial, desencadeia um processo aviltante de consumo e degradação do meio ambiente, gerando uma série de prejuízos para todo o planeta. E considerar esse contexto políticoeconômico torna-se central para pensar e elaborar ações relacionadas e direcionadas para a Educação Ambiental.

Não obstante esse conjunto de fatores degradantes do meio ambiente, as possibilidades e, principalmente, as lutas pela preservação, conservação e fruição sustentável do ambiente (natural e urbano) são dinâmicas pertinentes e significativas nesse contexto. O valor dessas lutas, quiçá, apresenta-se antes qualitativamente do que quantitativamente, isto é, pelo potencial e emergência, ora deliberadamente adotado pelos indivíduos e implementados em políticas públicas, ora imposto pelas "respostas" virulentas da própria natureza (furações, secas, enchentes, etc.). Significa dizer, ainda que esteja em curso uma política de governança que enfraqueça o meio ambiente, há uma busca em romper com esse modelo, e adotar uma postura que considere a justiça, a saúde, a cidadania, a liberdade, a vida como elementos essenciais das relações sociais.

Nesse sentido, ao considerar as mazelas existentes, todavia sem aquiescer frente a elas, têm-se estudos e propostas para o desenvolvimento da Educação Ambiental. Esta não emerge como redentora da sociedade, tampouco espera o fim dessa sociedade para então poder florescer, mas a Educação Ambiental, ou melhor, os indivíduos que a colocam em ação, apesar de reconhecerem as limitações, atuam no presente para alterar o cenário adverso.

A Educação Ambiental emerge e é eleita nesse trabalho como uma práxis fundamental para balizar as ações escolares, um caminho profícuo para aproximar a comunidade escolar com a natureza, passando a conhecê-la, preservá-la. Encontramos respaldo para o desenvolvimento dessa proposta na comunidade acadêmica, em autores como Layrargues (2000), Quintas (2004), Ruscheinsky (2004), Jacobi $(2003 ; 2005)$ e Sorrentino et al. (2005); no âmbito das políticas públicas, a lei no. 9.795, de 27 de abril de 1999, que dispõe sobre a Educação Ambiental e institui a Política Nacional de Educação Ambiental assinala o reconhecimento da necessária atuação do Estado na questão ambiental. Respaldo também indicado em programas de políticas educacionais, como o COM-VIDAS (Comissões de Meio Ambiente e Qualidade de Vida), que incentiva a formação de comissões nas escolas a fim de promover um espaço democrático e participativo para elaboração de propostas e ações da Educação Ambiental. 
Cabe destacar que a compreensão acerca da Educação Ambiental é complexa e nos remete à pluralidade. A Educação Ambiental pode ser entendida, simultaneamente, como um subcampo derivado do campo ambientalista e também como um campo relativamente autônomo (LAYRARGUES, LIMA; 2014, p. 25). Isso em razão de a Educação Ambiental se valer do campo ambientalista, de elementos simbólicos e institucionais significativos de sua identidade e formação. Por outro lado, ao analisarmos sua relação com o campo educacional, cultura, saberes, espaços escolarizados e práticas, evidencia-se que a Educação Ambiental tem peculiaridades que the atribuem um ethos específico (LIMA, 2011). Almejamos manter a perspectiva de relação entre o campo ambientalista e de Educação Ambiental, porém fazendo um recorte em nossa perspectiva e nos concentrando nessas peculiaridades e ethos da Educação Ambiental.

Para tanto, passamos a explicitar algumas características da Educação Ambiental e alterações que sofreram ao longo da história, porém sem a pretensão de fazer um estudo histórico, propriamente dito. Dessa forma, conforme Layrargues (2000), a Educação Ambiental primou, inicialmente, pela faceta não humana do meio ambiente. Dando destaque, portanto, aos saberes e conhecimentos biológicos e ecológicos. Sendo centrais os chamados problemas ambientais, tais como: efeito estufa; buraco na camada de ozônio; alterações na superfície da terra; exacerbações das mudanças climáticas; desflorestamento; queimadas; erosão do solo; areificação/desertificação; destruição de habitats; perda da biodiversidade; poluição; escassez de água potável; erosão (POLLARD, 2010). Esse enfoque foi (e permanece sendo) significativo, e muito contribuiu para o entendimento de fenômenos naturais. Em outra dimensão, cronologicamente mais recente, a Educação Ambiental é balizada, concomitantemente, por referências das ciências humanas e sociais, trazendo à tona conceitos e noções como a de cidadania, de desenvolvimento sustentável, de reciclagem e reaproveitamento, de ideologia, de participação e democracia (LAYRARGUES; LIMA; 2014).

Essa diversidade de enfoque e conceitos, a nosso ver, antes enriquece do que fragmenta as ações de Educação Ambiental. Pois, pela diferenciação, cria-se a possibilidade de alargar a base de indivíduos, grupos, comunidades que possam apresentar saberes e conhecimentos sobre como lidar com a questão ambiental. Para tanto, que consideramos profícuo, segundo Jacobi (2003, p.198), que a Educação Ambiental deva "ser vista como um processo de permanente aprendizagem que valoriza as diversas formas de conhecimento e forma cidadãos com consciência local e planetária".

O trabalho com a Educação Ambiental promove a escola como o espaço privilegiado para seu desenvolvimento. Nela é possível difundir e produzir saberes, além de envolver diferentes atores da comunidade escolar e local: estudantes, professores, gestores, mães, pais e responsáveis. Contudo, não é o único espaço. As atividades e experiências devem transcender o espaço escolar e englobar ações na natureza e em espaços urbanos. Isso, pois a "Educação Ambiental como formação e exercício de cidadania refere-se a 
uma nova forma de encarar a relação do homem com a natureza, baseada numa nova ética, que pressupõe outros valores morais e uma forma diferente de ver o mundo e os homens" (JACOBI, 2003, p. 10).

Nessa ótica, reiteramos o aspecto que se torna central na Educação Ambiental: a relação natureza-homem. É fundamental trabalharmos com essa relação, e não com apenas um dos polos, pois ampliamos nossas possibilidades de intervenção. Outrora, quando o enfoque recaía na natureza, aprendemos muito sobre fenômenos naturais como terremotos, tsunamis e outros, contudo pouco podemos fazer em relação a eles. Todavia, as pesquisas ao evidenciarem as ações humanas como geradoras de significativo impacto negativo sobre o meio ambiente, passamos a trilhar um caminho mais propositivo de preservação do planeta. E a Educação Ambiental passa a ser mediada por conceitos como o de cidadania. Ser cidadão é exercer seus direitos e reconhecer seus deveres, o que implica um senso de identidade e de coletividade. Identidade assinala as peculiaridades do ser, em especial, de caráter social e cultural, seus gostos, vontades, pensamento político. Todavia, identidade se constitui no bojo da coletividade, não se confunde com esta, mas estão intimamente relacionadas. Destacamos a questão cidadã em razão de Jacobi (2003) argumentar a favor de a Educação Ambiental estar articulada num projeto maior, no caso, a educação para a cidadania.

Tendo direitos e deveres, o cidadão, nessa reconfiguração naturezahomem, não apenas é consumidor. A natureza não é algo externo e distante, que possui problemas próprios. A natureza faz parte do seu ser, o constitui. Assim, as catástrofes ambientais hodiernas são vistas antes como consequências das ações humanas do que o curso natural do planeta. Essa perspectiva não só é profícua, mas também prudente, ao não delegar para um elemento metafísico e transcendental o desenvolvimento da humanidade. Dessa forma, aprendemos a cuidar, a ética do cuidado (BOFF, 1999) a preservar a natureza. Não se trata, exclusivamente, de deixá-la intacta, e sim de promover uma sociedade sustentável (RUSCHEINSKY, 2004).

Corrobora com essa perspectiva o trabalho de Sorrentino (1998), que chama a atenção para a necessidade de se articularem ações de Educação Ambiental baseadas nos conceitos de ética e sustentabilidade, identidade cultural e diversidade, mobilização e participação e práticas interdisciplinares. O caráter interdisciplinar é fundamental para tratarmos o tema do meio ambiente, tanto no campo da pesquisa quanto da prática pedagógica. Nas escolas, essa temática passa a não ser mais incumbência exclusiva dos docentes do componente curricular de ciências, mas efetua-se enquanto responsabilidade de todo o conjunto escolar, como manifesto nos Parâmetros Curriculares Nacionais (BRASIL, 1998). Dentre eles, realçamos as potencialidades da Educação Física, que não é vista como uma alternativa ou caminho paralelo, ela torna-se um dos eixos de formação da Educação Ambiental. Proposta que, à primeira vista, pode parecer audaciosa, mas queremos atentar para sua característica constituidora e motivadora da Educação Ambiental.

Revbea, São Paulo, V. 12, № 5: 156-169, 2017. 
Ao adotar-se o entendimento de que a Educação Ambiental é interdisciplinar, essa hermenêutica indica o rompimento com a hierarquia entre as diferentes descrições e linguagens sobre o mundo. Essas descrições e linguagens são postas horizontalmente. Dessa forma, ao adotarmos que a "perspectiva ambiental consiste num modo de ver o mundo no qual se evidenciam as inter-relações e a interdependência dos diversos elementos na constituição e manutenção da vida" (BRASIL, 1998, p. 173), temos a Educação Física buscando compreender como as pessoas não apenas veem, mas, por meio da linguagem corporal, expressam seus modos de relacionar com a natureza.

Destaca-se que não é qualquer modo de descrever e compreender a Educação Física que irá se articular com a Educação Ambiental. Para tanto, no intuito de vislumbrar possibilidade, cabe assinalar que compreendemos a Educação Física como campo de conhecimento e de prática pedagógica, perspectiva que rompe com a dicotomia teoria e prática. A Educação Física trata da cultura corporal de movimento, nessa perspectiva enfocamos as chamadas práticas corporais, ou seja, conjunto de ações criadas, apreendidas, apropriadas, ressignificadas, aperfeiçoadas ao longo da história, sendo culturalmente condicionadas e condicionantes (BETTI, 2009). Diferentemente é a noção de atividade física, que realça o deslocamento no tempo e espaço do corpo, priorizando características biológicas e o viés da física.

No bojo dessa cultura corporal de movimento, a historiografia da área reconhece a predominância dos esportes, destacadamente no século $X X$ (TABORDA DE OLIVEIRA, 2003; CASTELLANI FILHO, 1988). O fenômeno esportivo é então caracterizado pelos princípios da sobrepujança e das comparações objetivas (KUNZ, 1994). Isto é, uma competitividade exacerbada e o uso de espaços artificiais ou construídos pelo homem. Por essa via, esbarramos num paradigma que visa dominar o corpo (natureza) para submetê-lo a uma racionalidade instrumental. A natureza, tanto do meio ambiente quanto o próprio corpo do indivíduo, é relegado a objeto, e não sujeito, nessa acepção.

Concomitantemente, embora com menos visibilidade social, tem-se um movimento contra-hegemônico, no qual o modo de sociabilidade com a natureza, supracitado, não atende as necessidades dos indivíduos e coletividades. Almeja-se edificar, portanto, uma sociabilidade pautada na interdependência sujeito-natureza-sociedade, a "vitória" não é mais superar o adversário, ela pode significativamente tornar-se a demonstração de superação das adversidades existentes e eleitas pelos sujeitos (caso da escalada). Podemos, em certas situações, até abandonar a ideia de vitória, pois não há vencidos e vencedores, há uma interação saudável entre homem e natureza (exemplos no montanhismo, asa delta, entre outros).

São exemplos dessas novas sociabilidades os esportes de aventura ou práticas corporais de aventura e lazer. Embora permaneça o uso do termo esporte, seu significado é substancialmente alterado. Passando a se constituir 
mais como uma noção acerca do modo das pessoas interagirem entre si e com os espaços urbanos e naturais assumindo riscos (SPINK; SPINK, 2009).

Nesse contexto, de vínculo entre o ambiente-educação-corpo-lazeresporte, a Educação Ambiental é desenvolvida por processos de sensibilização pela e na natureza, incluindo, o reconhecimento de seu valor em si. E a Educação Física colabora na aproximação entre jovens (escolares) e natureza, que terão a oportunidade de manifestar e imaginar novas formas para essa comunicação e interação. Ademais, realizando o trabalho de envolvimento de diferentes atores (RUSCHEINSKY, 2004), o contato com a natureza tende a permitir que façam uma descrição densa, pois efetivando um trabalho multidisciplinar, outros campos de conhecimento poderão se inserir nessa dinâmica, fazendo com que estudantes aprendam, também, sobre aspectos ecológicos e geográficos, entre outros.

Portanto, a Educação Física mostra-se significativa no objetivo de despertar e instigar o contato com a natureza, ou mais, quiçá, fundir a noção de homem-natureza. Para tanto, conta com uma diversidade de objetivos e multiplicidade de atividades possíveis de serem realizadas. Destacamos os esportes na água, como a canoagem; na terra, a realização do trekking pelo rico bioma, as atividades de escalada e rapel nas encostas dos morros nos arredores da cidade.

Uma característica fundamental a ser considerada é que os esportes de aventura combinam o risco com a tecnologia, pois o risco não significa ação insana ou meramente espetacular, há procedimentos prévios anteriores a serem seguidos: verificação do equipamento e das condições climáticas, disposição corporal, alimentos e água para o percurso, entre outros. O risco é considerado por Spink e Spink (2009) um dos grandes impulsionadores para a realização de aventuras esportivas. Tais aventuras não são necessariamente pertinentes para o meio ambiente. Autores como Alves (2009) alertam que a prática desses esportes sem 0 devido acompanhamento pode, contraditoriamente, favorecer a degradação do espaço ao ser frequentado por um número de pessoas exagerado. Trata-se, portanto, não de impedir o acesso, mas de avaliar as condições de cada espaço e conscientizar o público, em especial, os jovens sobre os cuidados e formas de gestão do meio ambiente. Situação que mostra a importância de tratar o tema previamente e do necessário aprimoramento, formação contínua, dos professores de Educação Física. Isso reforça, também, o valor de criar as Comissões de Meio Ambiente e Qualidade de Vida, bem como a intervenção e promoção pela escola de ações e pesquisas voltadas para o desenvolvimento sustentável e formação de cidadãos críticos. Para tanto, concretizar o vínculo ambienteeducação-corpo-lazer-esporte é essencial para a produção de impactos positivos na formação ampliada e criativa dos jovens e adolescentes. 


\section{Breves notas para um trabalho docente que tematiza a Educação Ambiental na Educação Física}

Estabelecer o vínculo entre ambiente-educação-corpo-lazer-esporte foi um passo inicial (e não esgotado) para pensarmos e imaginarmos uma Educação Física-Ambiental. Diferentemente de perspectivas que buscam na "natureza intrínseca" do trabalho docente seus fundamentos, ousamos explorar a noção de imaginação de Richard Rorty (2009). Não se trata de uma descrição do mundo da fantasia, mas sobre a necessidade de ao identificar que o repertório de palavras e vocabulários são insuficientes para tornar as pessoas mais felizes e versões melhores de si próprias, é necessário imaginar essas novas formas. Nesse caso, acerca do debate da questão ambiental, ao notarmos os limites do trato do tema com ênfase na natureza e em dicotomia com o ser humano, o caminho foi alterar a abordagem do assunto.

O trabalho docente significa a atividade (teórico-prática) de um indivíduo que realiza um conjunto de ações cuja finalidade é conduzir um processo de aprendizagem, registra-se que ser realizado por um indivíduo não representa seu isolamento social, o trabalho docente tem uma dimensão coletiva, que são os valores sociais e culturais construídos ao longo da história sobre o que é ser docente/professor (BASSO, 1998). E como a Educação Física vem tratando a possibilidade de tratar pedagogicamente 0 meio ambiente? Qual o conjunto de ações que podem balizar o trabalho docente?

Uma questão interessante é abordada por Caetano e Leite (2004), sobre a relação Educação Física e Educação Ambiental ser tratada como modismo. Esse é um assunto que, digamos, pode ser um tema gerador que problematiza o modo do ser humano se relacionar com a natureza e que pode ser estudado em sala de aula. Caetano e Leite (2004) demonstram como uma visão reducionista da relação natureza/homem a entende como elementos distantes, e não reconhece o ecossistema humano, o homem como natureza. Como mostram Marinho e Inácio (2007, p. 57) "a concepção tradicional de meio ambiente não gera nenhuma lógica para um reencantamento da natureza". E no âmbito pedagógico o desdobramento dessa perspectiva reducionista é concentrar em áreas isoladas a difusão do saber ao invés da promoção do saber ambiental, a integração de saberes e a realização de trabalhos coletivos e interdisciplinares.

O trabalho de Domingues et al. (2011) realiza uma investigação sobre a relação Educação Física e Educação Ambiental. Nele são explicitados os objetivos, princípios e diretrizes construídos historicamente que balizam a Educação Ambiental. Mostram que Educação Ambiental se organiza a partir de princípios sistematizados pelo Tratado para as Sociedades Sustentáveis e Responsabilidade Global e pressupõe:

Ter como base o pensamento crítico e inovador, promovendo a transformação e a construção da sociedade; ser individual e coletiva, com propósito de formar cidadãos com consciência 
local e planetária, respeitando a autodeterminação dos povos e a soberania das nações; envolver uma perspectiva holística, enfocando a relação entre o ser humano, a natureza e o universo de forma interdisciplinar; estimular a solidariedade, a igualdade e o respeito aos direitos humanos, valendo-se da estratégia democrática e interação entre as culturas; integrar conhecimentos, aptidões, valores, atitudes e ações; converter cada oportunidade em experiências educativas das sociedades sustentáveis; ajudar a desenvolver uma consciência ética sobre todas as formas de vida com as quais compartilhamos este planeta, respeitar seus ciclos vitais e impor limites à exploração dessas formas de vida pelos seres humanos (DOMINGUES, 2011, p. 562-563).

Esses são pontos fundamentais para se pensar um trabalho docente na perspectiva da Educação Física-Ambiental, entretanto nota-se também limitações, dado a amplitude e diversidade de elementos a serem considerados. Nesse sentido, sob o risco de cair no reducionismo, mas também não pretendendo se perder nessa vastidão de aspectos, cabe realçar o trabalho da conscientização ambiental para "saber o que se faz como se faz e quais são os impactos destas ações para o meio no local e no global" (DOMINGUES et al, 2011, p. 565).

Pensamos que a conscientização ambiental encontra uma via instigante na aventura na natureza (MARINHO; INÁCIO, 2007), seja no lazer ou no esporte. Na descrição dos autores:

A busca pela aventura caracteriza-se pela emergência histórica de imagens, valores, conhecimentos, metáforas e paradoxos, intimamente atrelados à condição humana na sociedade contemporânea, os quais têm a singular capacidade de influenciar na vida social como um todo (MARINHO; INÁCIO, 2007, p. 60).

A conscientização ambiental alarga possibilidades, em especial, por ultrapassar o domínio da razão e abraçar as emoções, os aspectos estéticos. Assim podemos visualizar uma formação de corpo inteiro (FREIRE, 2009). A Educação Física, nessa situação, poderá proporcionar essas ricas experiências. Estamos cientes de que as atuais condições das escolas públicas podem impedir que a visita à natureza de fato aconteça, entretanto, a difusão dessas possibilidades que abrirão portas e caminhos, mesmo que não imediatamente. Ademais, conhecer os valores, as metáforas, o novo entendimento de esporte na natureza, bem como a forma de usar esses espaços são viáveis dentro das escolas. E não apenas no âmbito teórico, explorar o próprio espaço escolar e encontrar pontos de escalada, travessias, 
saltos, entre outros, podem se apresentar como uma aventura, desde que organizada pedagogicamente.

Outro tema instigante para ser tratado na ótica da Educação FísicaAmbiental é o lazer. Esse campo tem relação com a Educação Física, em certo aspecto, foram desenvolvidos juntos, mas o lazer é mais abrangente que essa faceta conectada à Educação Física. E em algum grau, são independentes. Esse entendimento se deve, em boa parte, em razão da explicitação por parte de autores como Parker (1978), que capta o lazer como fazendo um binômio com o trabalho. E desse modo, o lazer, podendo ser tratado, em linhas gerais, como mero subsidiário, complemento da parte séria da vida, que é o trabalho. No sentido oposto, o lazer é o grande cerne da vida, sendo o trabalho apenas o meio para chegar até ele. E uma terceira via, é trata-los como conciliáveis, um enriquecendo a perspectiva do outro.

Nesse último sentido, de conciliação entre lazer e trabalho, dado as condições históricas que limitam uma plena integração, o lazer pode tornar-se uma aspiração do ser humano, uma reivindicação social. A população não se contenta mais com a ideia de lazer como tempo livre, de descanso para retornar aos afazeres e a labuta, mas a desejam e querem como forma de cidadania, de participação cultural, fonte para a criação de mais e novas culturas (MARCELLINO, 1995).

Por essa trilha que o lazer desbrava para se encontrar o meio ambiente. Um espaço alvissareiro para a realização de atividades culturais, de imaginação, de exercício da cidadania. O lazer como possibilidade de sensibilização ambiental (CHAO, 2004), não se trata de se encantar no sentido frívolo, mas de se sentir pertencente a natureza, fundir-se em homem-natureza. Uma procura pela evolução como busca do mais humano, inventando sua identidade cultural a partir de intervenções em si mesmo e na natureza (VILLAÇA; GÓES, 1998).

As temáticas como a do lazer e esportes na natureza, mais especificamente tratadas pedagogicamente pelo professor de Educação Física, são potencializadas quando inseridas em um projeto de Educação Ambiental como política pública (SORRENTINO, 2005). Um exemplo é o projeto para implantação da Comissão de Meio Ambiente e Qualidade de Vida nas Escolas (COM-VIDAS), uma das ações estruturantes do Programa Vamos Cuidar do Brasil com as Escolas - Ministério da Educação.

O programa COM-VIDAS (2004, p.5-6) visa contribuir com uma Educação Ambiental que nos faça perceber "o meio ambiente como nossa vida, nosso corpo, as florestas, os animais, as águas, o ar, a terra; nossa escola, nossa rua e também as relações que estabelecemos com as outras pessoas e as outras culturas". É um programa destinado ao trabalho coletivo e em rede na escola, como exposto pela Política Nacional de Educação Ambiental - Lei no 9.795/1999, em seu artigo 10 - ao estabelecer que "a Educação Ambiental será desenvolvida como uma prática educativa integrada, contínua e permanente em todos os níveis e modalidades do ensino formal. A

Revbea, São Paulo, V. 12, № 5: 156-169 2017.

revista brasileira educação ambiental 
Educação Ambiental não deve ser implantada como disciplina específica no currículo de ensino". Nesse sentido, demanda de seus profissionais a postura de um educador ambiental.

Pudemos identificar em alguns autores uma perspectiva para que a Educação Ambiental tenha seu enfoque ampliado e, assim, abarcasse um número maior de profissionais. Entretanto, não basta, por parte das políticas públicas, exigir essa postura, é necessário fornecer subsídios. Como mostra Collares (2002) em seu estudo, há o interesse dos professores, contudo a formação que tiveram não deram as plenas condições para desenvolverem esse trabalho, além da carência de materiais e livros que contribuíssem para o trabalho.

Especificamente, no campo da Educação Física como componente curricular, problemas relacionados a formação docente decorre da própria perspectiva em que foram formados ou que adotaram na carreira profissional, é o caso de concepções, por exemplo, esportivizadas e recreacionista (DARIDO; NETO, 2005). Esses são modos de lidar com a atuação docente de modo centrado na prática, o que pode resultar no infrutífero "fazer por fazer", como se bastasse a simples movimentação para ser relevante, desconsiderando a necessária relação entre teoria e prática. $O$ trabalho docente, para não se resumir ao aspecto prático, precisa abarcar essas novas concepções explicitadas. Essas breves notas podem inquietar os docentes para explorar seu espaço escolar, bem como aventurar-se na natureza.

O debate realizado nesse trabalho buscou argumentar sobre como vem tornando-se imprescindível englobarmos e envolvermos diferentes atores sociais para lidar com o meio ambiente, sendo relevante o papel da escola e dos educadores ambientais. E educador ambiental não é um profissional específico, não é domínio restrito de uma área de conhecimento tampouco um nicho de mercado. Enfoque que demanda dos professores um trabalho tanto interdisciplinar quanto multidisciplinar, visando ofertar uma educação cheia de sentidos e significados, para que o estudo e conhecimento acerca do meio ambiente seja algo no qual os estudantes identifiquem a relevância, que se sintam participantes do processo, que compreendam seu papel fundamental, pois, do contrário, com a proliferação e ampliação da degradação ambiental, não terão mais recursos para a própria vida. Para tanto, as propostas de elaboração de projetos coletivos, como previsto nas ações do COM-VIDAS (BRASIL, 2004), a Educação Ambiental articulada a perspectiva da educação para a cidadania (JACOBI, 2003), a Educação Ambiental como política pública (SORRENTINO et al, 2005), a significativa relação entre Educação Ambiental e educação física (DOMINGUES, 2011) e os esportes de aventuras e atividades de lazer na natureza como caminho para a Educação Ambiental (MARINHO, INÁCIO, 2007; MARINHO, 2004), são aspectos pertinentes para pensar a Educação Física como caminho para a Educação Ambiental, uma Educação Física-Ambiental. 


\section{Referências}

ALVES, F.D. Impacto e preservação: prós e contras da prática esportiva em unidades de conservação. In: DIAS, C. A. G.; ALVES JUNIOR, E. D (orgs.). Em busca da aventura: olhares sobre esporte, lazer e natureza. Niterói: EdUFF, 2009.

BASSO, I.S. Significado e sentido do trabalho docente. Cadernos CEDES, v. 19, n. 44, Campinas 1998.

BETTI, M. Educação Física Escolar: ensino e pesquisa-ação. ljuí: Ed. Unijuí, 2009.

BOFF. L. Saber Cuidar: ética do humano - compaixão pela Terra. Petrópolis: Vozes, 1999

BRASIL. Comissão de Meio Ambiente e Qualidade de Vida (COM-VIDA). Série documentos técnicos, $\mathrm{n}^{\circ} 10$. Órgão Gestor da Política Nacional de Educação Ambiental. Brasília, DF: 2007.

BRASIL. Formando Com-Vida Comissão do Meio Ambiente e Qualidade de Vida na Escola: construindo Agenda 21 na Escola / Ministério da Educação, Ministério do Meio Ambiente. - Brasília: MEC, Coordenação Geral de Educação Ambiental, 2004.

BRASIL. Parâmetros curriculares nacionais: terceiro e quarto ciclos: apresentação dos temas transversais / Secretaria de Educação Fundamental. Brasília: MEC/SEF, 1998.

CASTELLANI FILHO, L. Educação Física no Brasil: a História que não se conta. Campinas, SP: Papirus, 1988.

CHAO, C. H. N. Relação homem/natureza e o lazer como uma possibilidade de sensibilização da questão ambiental. Motrivivência, ano XVI, n. 22, 2004.

COLLARES, M.E.B. A Educação Ambiental como tema inter e transdisciplinar no processo educacional: um estudo de caso no município de Petrópolis. 2002. 102 f. Dissertação (Mestrado em Sistemas de Gestão) - Departamento de Engenharia de Produção, Universidade Federal Fluminense, Niterói, 2002.

DARIDO, S.C.; NETO, L.S. O contexto da Educação Física na escola. In: DARIDO, S.C.; RANGEL, I.C.A. (orgs.). Educação Física na escola: implicações para a prática pedagógica. Rio de Janeiro: Guanabara Koogan, 2005.

DOMINGUES, S.C. et al. Educação Ambiental e educação física: possibilidades para a formação de professores. Revista Brasileira de Ciências do Esporte, Florianópolis, v. 33, n. 3, 2011.

DRAIBE, S. M. Avaliação de implementação: esboço de uma metodologia de trabalho em políticas públicas. In: BARREIRA, M.C.R.N.; CARVALHO, M.C.B. (orgs). Tendências e perspectivas na avaliação de políticas e programas sociais. São Paulo: ICC/PUC-SP, 2001. 
FREIRE, J.B. Educação de corpo inteiro: teoria e prática da Educação Física. São Paulo: Scipione, 2009. (Coleção Pensamento e Ação na sala de aula).

JACOBI, P. Educação Ambiental, Cidadania e Sustentabilidade. Cadernos de Pesquisa. n. 118, 2003.

JACOBI. P. Educação Ambiental: o desafio da construção de um pensamento crítico, complexo e reflexivo. Educação e Pesquisa, São Paulo, v. 31, n. 2, 2005.

KUNZ. E. Transformação didático-pedagógica do esporte. ljuí: Ed. UNIJUÍ, 1994.

LAYRARGUES, P.P. Educação para a gestão ambiental: a cidadania no enfrentamento político dos conflitos socioambientais. In: P. P. LAYRARGUES; LOUREIRO, C.F.B.; CASTRO, R.S. (Org.). Sociedade e Meio Ambiente: a Educação Ambiental em debate. 1. ed. São Paulo: Cortez, 2000.

LAYRARGUES, P.; LIMA, G.F.C. As macrotendências político-pedagógicas da Educação Ambiental brasileira. Ambiente \& Sociedade. São Paulo V. 27, n. 1, 2014.

LIMA, G.F. Educação Ambiental no Brasil: Formação, Identidades e Desafios. Campinas, SP: Papirus, 2011.

MARCELLINO, N.C. A Ação Profissional no Lazer, sua Especificidade e seu Caráter Interdisciplinar. In: MARCELLINO, N.C. (Org). Lazer: Formação e atuação profissional. Campinas, SP: Papirus, 1995.

MARINHO, A. Atividades na natureza, lazer e Educação Ambiental: refletindo sobre algumas possibilidades. Motrivivência, Florianópolis (SC), n.22, p. 4769, 2004.

MARINHO, A. INÁCIO, U.L.D. Educação física, meio ambiente e aventura: um percurso por vias instigantes. Revista Brasileira de Ciências do Esporte, Campinas, v. 28, n. 3, 2007.

POLLARD. D. (Org.) Relatório Planeta Vivo 2010: Biodiversidade, biocapacidade e desenvolvimento. Tradução Marsel de Souza. WWF Internacional, $2010 . \quad$ Disponível em: $<$ http://assets.wwfbr.panda.org/downloads/08out10 planetavivo relatorio2010 completo n9.pdf >. Acesso em: 16 fev. 2015.

QUINTAS, J.S. Educação no processo de gestão ambiental: uma proposta de Educação Ambiental transformadora e emancipatória. In: LAYRARGUES, P.P. (coord.). Identidades da Educação Ambiental brasileira / Ministério do Meio Ambiente. Brasília: Ministério do Meio Ambiente, 2004.

RORTY, R. Filosofia como política cultural. São Paulo: Martins fontes, 2009.

RUSCHEINSKY. A. Atores Sociais e Meio Ambiente. In: LAYRARGUES, P.P. (coord.). Identidades da Educação Ambiental brasileira / Ministério do Meio Ambiente. Brasília: Ministério do Meio Ambiente, 2004. 
SORRENTINO, M. et al. Educação Ambiental como política pública. Educação e Pesquisa, São Paulo, v. 31, n. 2, p. 285-299, 2005.

SPINK, M.J.; SPINK, S.P.P. Aventura esportiva na modernidade tardia. In: DIAS, C.A.G.; ALVES JUNIOR, E.D (orgs.). Em busca da aventura: olhares sobre esporte, lazer e natureza. Niterói: EdUFF, 2009.

TABORDA DE OLIVERIA. M.A. Educação Física Escolar e Ditadura Militar no Brasil: (1968-1984): entre a adesão e a resistência. Bragança Paulista: EDUSF, 2003.

VILLAÇA, N.; GÓES, F. Em nome do corpo. Rio de Janeiro: Rocco, 1998. 